\title{
Genotype $\times$ Environment Interaction for Pod Yield in Groundnut
}

\author{
Iramma V. Goudar, U. Roopa, Guruprasad Hiremath, B.S. Yenagi and H.L. Nadaf* \\ AICRP on Groundnut, Oilseed scheme, Main Agricultural Research Station, University of \\ Agricultural Sciences, Dharwad, Karnataka, India \\ *Corresponding author
}

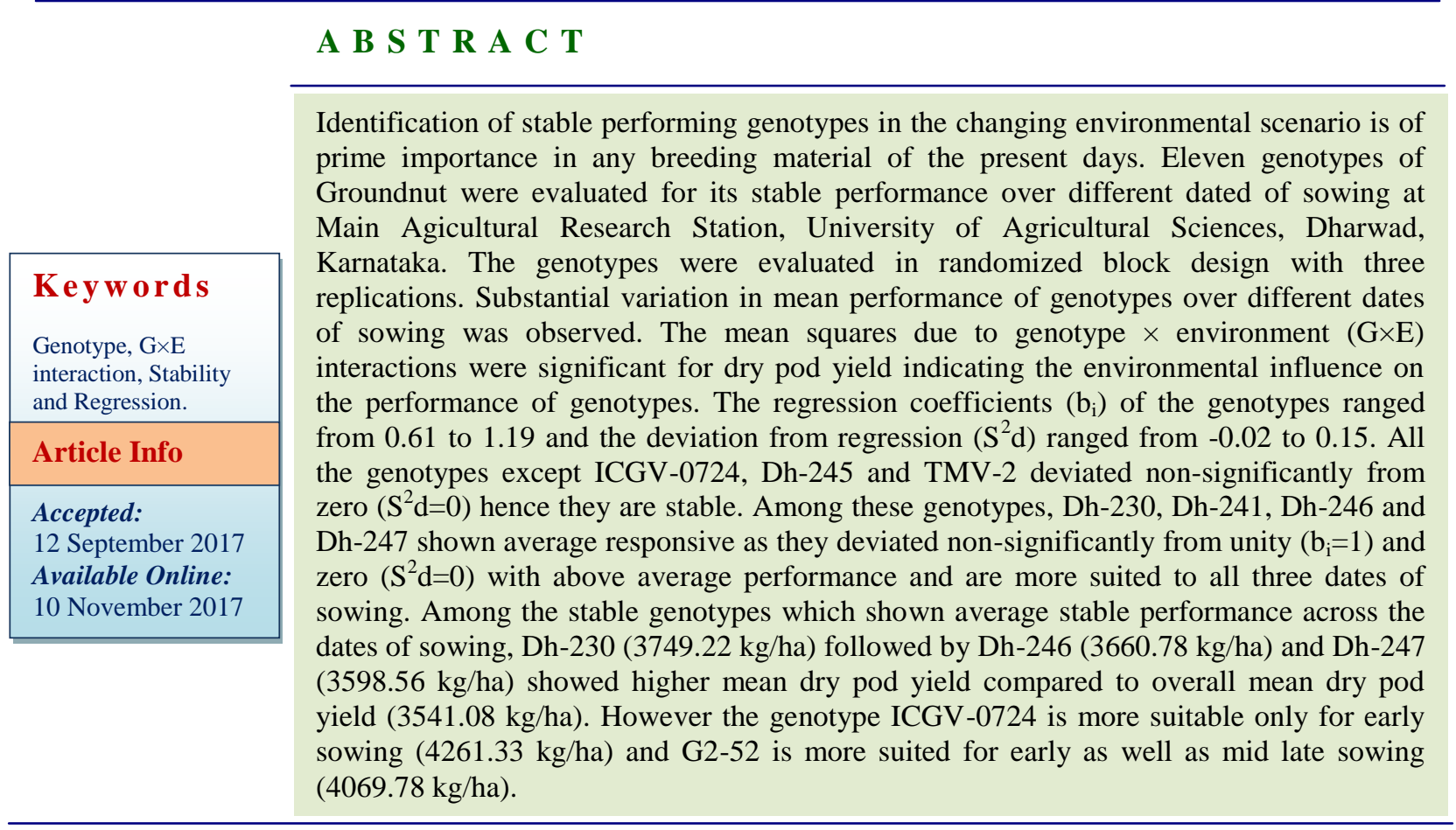

\section{Introduction}

Groundnut (Arachis hypogaea. L) is one among the nine important crops of the world which is native to Brazil in South America and presently cultivated throughout tropical, subtropical and warm temperate regions of the world. It is mainly grown by resourcepoor farmers in Africa and Asia to produce edible oil (48-50\%) and for human consumption. It belongs to Leguminosae or Fabaceae family, a self-pollinating crop with basic chromosome number ten $(2 n=4 x=40)$
(Stebbins 1957; Stalker and Dalmacio 1986) and genome size $2800 \mathrm{Mb}$ (Guo et al., 2009).

In India, the crop is grown in about 4.60 million hectares with a production of 6.73 million tonnes with a productivity of $1460 \mathrm{~kg}$ per hectare (Anon., 2015). Karnataka is one of the five important states growing groundnut in India. It is grown in an area of about 0.65 million hectares with a production of 0.50 million tonnes and productivity of 769 
$\mathrm{kg}$ per ha (Anon., 2015). Low productivity of groundnut in the country is attributed to several constraints and one among those is poor adoption of improved varieties and their inconsistent performance over range of environments, as the crop is largely cultivated as rainfed crop (Gadgil et al., 2012). Therefore, it has become necessary to develop varieties with attributes such as wide adaptability.

The consistent performance of a genotype over a range of environments is essential for a wide stability of a variety. Stability of genotypes depends upon maintaining expression of certain morphological and physiological attributes and allowing others to vary, resulting in $\mathrm{G} \times \mathrm{E}$ interactions. $\mathrm{G} \times \mathrm{E}$ interaction has a masking effect on the performance of a genotype and hence the relative ranking of the genotype do not remain the same over number of environments. Dixon et al., (1994) stated that GxE interaction is the change in a cultivar's relative performance over environments, which results from differential response of the cultivar, to various edaphic, climatic and biotic factors. GxE interaction occurs in two ways. Firstly the difference between genotypes vary without alteration in their rank i.e. GxE interaction is present because one cultivar yields more than another cultivar in all the environments, and secondly the ranking between cultivars changes across environments i.e. one cultivar will be more productive in one environment, while the other cultivar is more productive in another environment. GxE is a phenomenon that is very important and is of significance to plant breeders, agronomist and farmers all over the world. Breeding materials can be selected and assessed on the basis of their different responses to the environments. Studying of gxe interaction is very important to plant breeders because this interaction it can limit the progress in the selection process and since it is a basic cause of differences between genotypes for yield stability. Understanding the cause of GxE interaction is important to help in selecting varieties with the best adaptation and that can give stable yields. Linnemann et al., (1995) stated that it is important to understand crop development in relation to biophysical conditions and changes in season when selecting well-adapted genotypes and correct planting date.

It is generally agreed that the more stable genotypes adjust their phenotypic responses to provide some measure of uniformity in spite of environmental fluctuations. Therefore, an attempt has been made in present study to evaluate different groundnut genotypes across the different date of sowing to know the role of $\mathrm{G} \times \mathrm{E}$ interactions and also to analyze the stability of genotypes for different traits.

\section{Materials and Methods}

The present investigation comprising twelve genotypes (Dh-230, Dh-232, Dh-241, ICGV0724, Dh-243, Dh-245, Dh-246, Dh-247, GPBD-4, G2-52 and TMV-2) of groundnut were evaluated for their stable performance over three different environments created by different dates of sowing ( $11^{\text {th }} \mathrm{July}\left(\mathrm{E}_{1}\right), 22^{\text {nd }}$ $\operatorname{July}\left(E_{2}\right)$ and $4^{\text {th }} \operatorname{August}\left(E_{3}\right)$ 2014) at MARS, UAS, Dharwad during kharif 2014. The genotypes were evaluated in randomized block design (RBD) with three replications. Each experimental unit of $4 \mathrm{~m} \times 4 \mathrm{~m}$ bed size with $45 \times 10 \mathrm{~cm}^{2}$ inter and intra row spacing. The recommended package of practices and plant protection measures to raise a good crop were timely and uniformly applied.

Combined analysis of variance over the dates of sowing was estimated by assuming replications effects as random and genotypes effect as fixed effects. The phenotypic stability parameters, linear regression 
coefficient (b value), and deviation from regression $\left(\mathrm{S}^{2} \mathrm{~d}\right)$ of genotype means over environment index were computed as suggested by Eberthart and Russell (1966). This model considered both linear $(b i)$ and non-linear $\left(S^{2} d i\right)$ components of $\mathrm{G} \times \mathrm{E}$ interactions for the prediction of performance of the individual genotype.

\section{Results and Discussion}

The results of analysis of variation revealed that, the mean sum of squares due to varieties were significant for all the characters studied except dry pod yield ( $\mathrm{kg} / \mathrm{net}$ plot), Kernal yield (kg/net plot) and SMK $(\%)$ indicating the presence of substantial amount of variation in the material used for present investigation. The mean sum of squares due to environments was significant for all the characters indicating that the environments were quite variable. The significant mean squares due to genotpes $\times$ environment $(\mathrm{G} \times \mathrm{E})$ interactions were observed for all the characters except SMK (\%) and Oil content (\%) (Table 1) indicating the influence of environment on the genotypes evaluated. The significant genotype $\times$ environment $(\mathrm{G} \times \mathrm{E})$ interactions for various traits were also reported by Hariprasana et al., (2008), Pradhan et al., (2010) and Patil et al., (2014).

The significant mean squares due to environment plus genotype $x$ environments $(\mathrm{E}+\mathrm{G} \times \mathrm{E})$ were recorded for all the characters except SMK (\%) and Oil content (\%) suggesting that, distinct nature of environments and genotype $\times$ environment interactions in phenotypic expression. Similar results of significant environment + (genotype $x$ environment interactions) for various traits was reported by Joshi et al., (2003) and Patil et al., (2014). The mean squares due to $\mathrm{G} \times \mathrm{E}$ interactions were partitioned into linear and non-linear components. The significant environment (linear) was observed for all the characters, indicating that major environmental differences were present under all three environments (dates of sowing) studied. While, the significant mean squares due to genotypes $\times$ environments (linear) was observed only for shelling per cent and 100 seed weight $(\mathrm{g})$. However, the magnitude of mean squares for environment (linear) was higher compared to genotypes $x$ environments (linear) which indicated that, linear response of environment account for the major part of total variation for all the characters studied and which may be responsible for high adaptation. Similar results were also reported by Habib et al., (1986), Chuni Lal et al., (2006), Thaware (2009), Pradhan et al., (2010) and Patil et al., (2014). The mean squares due to pooled deviation (Non-liner) were significant for dry pod yield $(\mathrm{kg} / \mathrm{net}$ plot) and kernel yield (kg/ net plot) (Table 1). These results suggested that both linear and non-linear components played vital role in building up of total $\mathrm{G} \times \mathrm{E}$ interaction for various yield and yield attributing traits.

\section{Stability parameters for dry pod yield}

The regression coefficients $\left(b_{i}\right)$ of the geneotypes ranged from 0.61 to 1.19 and the deviation from regression $\left(\mathrm{S}^{2} \mathrm{~d}\right)$ ranged from 0.02 to 0.15 . The genotypes, Dh-232 and G252 expressed regression coefficient less than unity $(\mathrm{bi}<1)$ with mean values higher than population mean, while the genotype GPBD-4 exhibited regression greater than unity (bi $>1)$ (Table 2). Genotypes with regression coefficient less than unity $(\mathrm{bi}<1)$ and more than unity (bi>1) are expected to show stability for dry pod yield in unfavourable and favourable environments, respectively. Similar finding were also reported by Habib et al., (1986), Senapati et al., (2004), Chuni Lal et al., (2006), Hariprasana et al., (2008), Pradhan et al., (2010) and Patil et al., (2014). The genotypes, Dh-230, ICGV-07214, Dh246 and Dh-247 exhibited regression coefficient nearly equal to unity (bi $\approx 1$ ) with higher mean than population mean (Table 2). 
Int.J.Curr.Microbiol.App.Sci (2017) 6(11): 1566-1571

Table.1 Analysis of variance for phenotypic stability in groundnut

\begin{tabular}{|c|c|c|c|c|c|c|c|c|c|c|}
\hline Source of variation & $\mathrm{df}$ & $\begin{array}{l}\text { DPY }(\mathrm{kg} / \mathrm{net} \\
\text { plot })\end{array}$ & $\mathrm{SH}(\%)$ & $\begin{array}{l}\mathrm{KY}(\mathrm{kg} / \mathrm{net} \\
\text { plot })\end{array}$ & $\begin{array}{l}\text { SMK } \\
(\%)\end{array}$ & $\begin{array}{l}100 \text { Seed wt } \\
(\mathrm{g})\end{array}$ & Oil (\%) & $\mathrm{KY}(\mathrm{kg} / \mathrm{ha})$ & $\begin{array}{l}\text { Oil yld } \\
(\mathrm{kg} / \mathrm{ha})\end{array}$ & DPY (kg/ha) \\
\hline Rep within Env. & 6 & 0.02 & $1.11 *$ & 0.01 & 3.93 & 2.44 & 0.35 & 66320.61 & 15024.38 & 125448.04 \\
\hline Varieties & 10 & 0.10 & $8.25 * *$ & 0.05 & 6.99 & $7.16^{*}$ & $3.39 * *$ & $379570.46^{* *}$ & $95620.94 *$ & $675304.43 *$ \\
\hline Env.+(Var.*Env.) & 22 & $0.37 * *$ & $2.30 * *$ & $0.21 * *$ & 11.91 & $4.78 *$ & 0.22 & $357765.78 *$ & $80159.17 *$ & $635028.11 *$ \\
\hline Environments & 2 & $3.82 * *$ & $9.59 * *$ & $2.15^{* *}$ & $72.61 * *$ & $15.28 * *$ & $1.22 *$ & $2624697.71 * *$ & $605963.97 * *$ & $4957246.55 * *$ \\
\hline Var.* Env. & 20 & 0.034 & $1.57 * *$ & 0.02 & 5.84 & 3.73 & 0.12 & 131072.59 & 27578.69 & 202806.27 \\
\hline Environments(Lin.) & 1 & $7.64 * *$ & $19.19 * *$ & $4.30 * *$ & $145.23 * *$ & $30.56 * *$ & $2.44 * *$ & $5249395.43 * *$ & $1211927.94 * *$ & $9914493.11 * *$ \\
\hline Var.*Env.(Lin.) & 10 & 0.02 & $2.82 * *$ & 0.01 & 5.80 & $5.65^{*}$ & 0.08 & 119232.67 & 26301.38 & 181333.62 \\
\hline Pooled Deviation & 11 & $0.04^{*}$ & 0.30 & $0.02 *$ & 5.34 & 1.65 & 0.15 & 129920.47 & 26232.72 & 203889.92 \\
\hline Pooled Error & 60 & 0.01 & 0.88 & 0.01 & 2.88 & 1.40 & 0.08 & 69554.32 & 14987.15 & 112665.52 \\
\hline
\end{tabular}

$*$ and $* *$, probability at 0.05 and 0.01

Dry pod yield (DPY), Shelling per cent (SH), Kernal yield (KY) 
Table.2 Estimates of phenotypic stability parameters for dry pod yield in groundnut

\begin{tabular}{|r|l|c|c|c|c|}
\hline S1.No & Genotype & Mean DPY (kg/plot) & Mean DPY (kg/ha) & $\beta \mathrm{i}$ & $\sigma^{2} \mathrm{di}$ \\
\hline 1 & Dh-230 & 1.53 & 3749.22 & 1.19 & -0.01 \\
\hline 2 & Dh-232 & 1.49 & 3774.56 & $0.83^{*}$ & -0.02 \\
\hline 3 & Dh-241 & 1.29 & 3139.44 & 1.09 & -0.01 \\
\hline 4 & ICGV-07214 & 1.71 & 4261.33 & 1.09 & $0.15^{* *}$ \\
\hline 5 & Dh-243 & 1.43 & 3527.67 & 1.06 & 0.00 \\
\hline 6 & Dh-245 & 1.27 & 3106.67 & 1.04 & $0.10^{*}$ \\
\hline 7 & Dh-246 & 1.47 & 3660.78 & 0.95 & -0.01 \\
\hline 8 & Dh-247 & 1.47 & 3598.56 & 1.19 & -0.01 \\
\hline 9 & GPBD-4 (C) & 1.43 & 3516.00 & $1.13^{*}$ & -0.02 \\
\hline 10 & G2-52 (C) & 1.60 & 4069.78 & $0.82^{*}$ & -0.02 \\
\hline 11 & TMV-2 (C) & 1.01 & 2547.89 & 0.61 & $0.09^{*}$ \\
\hline & Mean & 1.43 & 3541.08 & 1.00 & \\
\hline
\end{tabular}

C- Checks

Table.3 Mean performance for dry pod yield ( $\mathrm{kg} / \mathrm{ha}$ ) over different dates of sowing

\begin{tabular}{|r|l|c|c|c|c|}
\hline & Genotype & Env1 & Env2 & Env3 & General Mean \\
\hline 1 & Dh-230 & 4407.3 & 4176 & 2664.3 & 3749.222 \\
\hline 2 & Dh-232 & 4014.7 & 3884.3 & 3424.7 & 3774.556 \\
\hline 3 & Dh-241 & 3548.3 & 3842.7 & 2027.3 & 3139.444 \\
\hline 4 & ICGV-07214 & 5252 & 3988.7 & 3543.3 & 4261.333 \\
\hline 5 & Dh-243 & 4148 & 3810.3 & 2624.7 & 3527.667 \\
\hline 6 & Dh-245 & 3037 & 4171.7 & 2111.3 & 3106.667 \\
\hline 7 & Dh-246 & 4133.3 & 3819.3 & 3029.7 & 3660.778 \\
\hline 8 & Dh-247 & 4251.7 & 4088.3 & 2455.7 & 3598.556 \\
\hline 9 & GPBD-4 (C) & 3940.7 & 4143.3 & 2464 & 3516 \\
\hline 10 & G2-52 (C) & 4088.7 & 4259 & 3861.7 & 4069.778 \\
\hline 11 & TMV-2 (C) & 2178 & 3243.7 & 2222 & 2547.889 \\
\hline & Environment Index & 367.98 & 406.86 & -774.8 & \\
\hline
\end{tabular}

C- Checks

All the genotypes except ICGV-0724, Dh-245 and TMV-2 deviated non-significantly from zero $\left(\mathrm{S}^{2} \mathrm{~d}=0\right)$ hence they are stable and indicating their predictable behaviour. Among the genotypes studied, Dh-230, Dh-241, Dh246 and Dh-247 shown average responsive as they deviated non-significantly from unity $\left(b_{i}=1\right)$ and zero $\left(S^{2} d=0\right)$ with above average performance and are more suited to all three dates of sowing (Table 3). Among the stable genotypes which shown average stable performance across the dates of sowing, Dh-
$230(3749.22 \mathrm{~kg} / \mathrm{ha})$ followed by $\mathrm{Dh}-246$ (3660.78 kg/ha) and Dh-247 (3598.56 kg/ha) showed higher mean dry pod yield compared to overall mean dry pod yield (3541.08 $\mathrm{kg} / \mathrm{ha})$.

However the genotype ICGV-0724 is more suitable only for early sowing $(4261.33 \mathrm{~kg} / \mathrm{ha})$ and G2-52 is more suited for early as well as mid late sowing (4069.78 kg/ha). These genotypes could be used in further breeding improvement programme. 


\section{References}

Anonymous, 2015, INDIASTAT, Ministry of Agriculture and Farmers Welfare, Govt. of India

Chuni Lal, R., Rathnakumar, A.L., Hariprasanna, K., Gor, H.K., Chikani, B.M., 2006. Early maturing groundnut advanced breeding lines with high day1 productivity under rainfed situations. e-journal. icrisat.org 5(1): 4.

Dixon, A.G.O., R. Asiedu \& S.K. Hahn, 1994. Genotypic stability and adaptability: analytic methods and implications for cassava breeding for low input agriculture. In: Tropical root crops in a developing economy. F. Ofori and S.K. Hahn (Eds.), pp.130-137. Proceedings of the 9th Symposium of the International Society for Tropical Root Crops, 20-26 October 1991, Accra, Ghana.

Eberhart, S.A., Russel, W.A., 1966. Stability parameters for comparing varieties. Crop Science, 6: 36-40.

Gadgil, S., Seshagiri Rao, P.R., Joshi, N.V., Sridhar, S., 1995. Forecasting rain for groundnut farmers-How good is good enough? Current Science, 68(3): 301309.

Habib, A.F., Nadaf, H.L., Kulkarni, G.K., Nadiger, S.D., 1986. Stability analysis of pod yield in bunch groundnut. Journal of Oilseeds Research, 3: 46-50.

Joshi, H.J., Vekaria, G.B., Mehta, D.R., 2003. Stability analysis for morphophysiological traits in groundnut. Legume Research, 26(1): 20-23.

Linnemann, A.R., E. Westphal \& M. Wessel, 1995. Photoperiod regulation of development and growth in bambara groundnut (Vigna subterranea). Field Crops Research 40(1):39-47.

Patil, A. S., Nandanwar, H. R., Punewar, A. A. and Shah, K. P., 2014. Stability for yield and its component traits in Groundnut (Arachis hypogaea L.). Intl. J. Bio-resource and Stress Management, 5(2):240-245.

Pradhan, K., Das, P.K., Patra, R.K., 2010. Genotype $\times$ environment interaction for pod yield and components of groundnut varieties in warm sub-humid climate and moderately acidic soil. Indian Journal of Genetics, 70(2): 201- 203.

Senapati, B.K., Maity, D., Sarkar, G., 2004. Stability evaluation of summer groundnut (Arachis hypogaea L.) under coastal saline zone of west Bengal. Legume Research 27(2): 103-106.

Thaware, B.L., 2009. Stability analysis for dry pod yield in Spanish bunch groundnut. Agricultural Science Digest 29(3): 221-223.

\section{How to cite this article:}

Iramma V. Goudar, U. Roopa, Guruprasad Hiremath, B.S. Yenagi and Nadaf, H.L. 2017. Genotype $\times$ Environment Interaction for Pod Yield in Groundnut. Int.J.Curr.Microbiol.App.Sci. 6(11): 1566-1571. doi: https://doi.org/10.20546/ijcmas.2017.611.187 